\title{
ANALISIS SIFAT MEKANIS BAJA KARBON MENENGAH AKIBAT PROSES AUSTENISASI TEMPERING
}

\author{
Nyoto Lestari*, Helmy Purwanto, Muhammad Dzulfikar \\ Jurusan Teknik Mesin, Fakultas Teknik, Universitas Wahid Hasyim \\ Jl. Menoreh Tengah X/22, Sampangan, Semarang 50236. \\ *Email: nyotolestari@gmail.com
}

\begin{abstract}
Abstrak
Perlakuan panas (heat treatment) didefinisikan sebagai kombinasi proses pemanasan dan pendinginan untuk mendapatkan sifat-sifat tertentu pada baja atau paduan lainnya. Salah satu proses perlakuan panas tersebut dengan proses quenching dan tempering. Proses ini dilakukan pada temperatur austenite $700^{\circ} \mathrm{C}, 800^{\circ} \mathrm{C}, 900^{\circ} \mathrm{C}$ dengan media pendingin celup oli, kemudian di lanjutkan proses tempering pada temperatur $100^{\circ} \mathrm{C}, 200^{\circ} \mathrm{C}, 300^{\circ} \mathrm{C}$, dan $400{ }^{\circ} \mathrm{C}$ dengan waktu penahanan 15 menit. Hasil pengujian pada uji struktur mikro memperlihatkan bahwa fasa yang banyak terlihat adalah fasa perlit, sedangkan fasa martensit jarang ditemukan. Hasil pengujian kekerasan memperlihatkan bahwa nilai terting gi adalah 591 HVN terdapat pada temperatur austenite $900^{\circ} \mathrm{C}$ dan di tempering pada temperatur $200{ }^{\circ} \mathrm{C}$. Hasil pengujian tarik mendapatkan Maksimal Stress tertinggi pada temperatur austenite $900{ }^{\circ} \mathrm{C}$ dan temperatur tempering $100{ }^{\circ} \mathrm{C}$ dengan nilai $961 \mathrm{MPa}$. Pengujian impak mendapat nilai $0,40 \mathrm{~J} / \mathrm{mm}^{2}$ yang terdapat pada temperatur austenite $900^{\circ} \mathrm{C}$ dan temperatur tempering $400^{\circ} \mathrm{C}$. Proses tempering dapat menurunkan nilai kekerasan dan kekuatan tarik dan pada uji impak nilai kekerasan meningkat. Sementara hasil mikro struktur memperlihatkan bahwa jumlah fasa-fasenya hampir sama dengan raw material.
\end{abstract}

Kata Kunci: perlakuan panas, baja karbon menengah, induksi, kekuatan tarik, impak.

\section{PENDAHULUAN}

Baja S45 C banyak dipakai dalam industri permesinan dan bahkan sekarang mulai dipakai dalam dunia kemiliteran (Helmy Purwanto dkk., 2016). Menurut (Handoyo, 2015) proses quenching dengan media pendinginan air menghasilkan sifat baja karbon yang lebih keras dibandingkan dengan oli. Heat treatment dapat dilakukan dengan banyak cara, misalnya saja pemanasan sampai suhu tertentu pada satu permukaan hingga mencapai suhu (Yurianto dkk., 2018) tertentu lalu didinginkan dengan media pendingin (proses quenching). Media quenching yang dipakai adalah oli dan air.

Menurut (Suroto \& Sudibyo, 1983) menyebutkan, tempering adalah proses pemanasan kembali suatu logam yang telah dikeraskan melalui proses quenching pada suhu di bawah suhu kritisnya selama waktu tertentu dan didinginkan secara perlahan-lahan (Mizhar \& Suherman, 2011). Tujuan proses ini adalah untuk mengurangi internal stress, mengubah susunan, mengurangi kekerasan dan menaikkan keuletan logam sehingga didapatkan perpaduan yang tepat antara kekerasan dan keuletan logam uji. Baja S45C
Steel (JIS: Japanese Industrial Standard) merupakan jenis baja "Medium Carbon Steel" yaitu baja mempunyai kandungan unsur karbon menengah 0,3-0,6\% C dan mempunyai kekuatan tarik $568 \mathrm{MPa}$, yield stress $343 \mathrm{Mpa}$ dan kekerasan 167-229 HB (Sularso, 2004). Material tahan peluru atau armor adalah material yang mampu menahan laju balistik yang dikeluarkan dari sebuah senapan $(\mathrm{H}$ Purwanto, 2011).

Pada penelitian ini bertujuan untuk meningkatkan sifat mekanik dari plat baja S45C agar mencapai sifat mekanik seperti plat baja anti peluru dengan cara heat treatment quenching dan tempering (surface hardening) dengan pemanasan menggunakan mesin pemanas induksi. Setelah itu spesimen diuji untuk mengetahui perubahan pada struktur mikronya, kekerasan, kekuatan tariknya dan juga ketangguhannya (toughness).

\section{METODE PENELITIAN}

Bahan yang dipakai dalam penelitian ini adalah baja S45C dengan komposisi unsur paduan yang ditunjukkan pada Tabel 1 . Kemudian spesimen di heat treatment dengan pemanas induksi dengan suhu austenisasi 700 
${ }^{\circ} \mathrm{C}, 800{ }^{\circ} \mathrm{C}, 900{ }^{\circ} \mathrm{C}$ lalu masing- masing dicelup ke dalam oli Setelah itu plat dipotong dengan mesin wire cut agar menjadi spesimen untuk uji struktur mikro, uji kekerasan , uji tarik dan uji impak sesuai standar (ASTM E8, 2010). Kemudian masing-masing variabel di temper dengan suhu $100^{\circ} \mathrm{C}, 200^{\circ} \mathrm{C}, 300^{\circ} \mathrm{C}, 400^{\circ} \mathrm{C}$., setelah itu dilakukan pengujian kemudian hasilnya diambil kesimpulan. Diagram alur penelitian akan ditunjukkan pada Gambar 1.

Tabel 1. Komposisi paduan baja S45C

\begin{tabular}{cc}
\hline Unsur & Komposisi (\%) \\
\hline $\mathrm{C}$ & 0.4667 \\
$\mathrm{Mn}$ & 0,5584 \\
$\mathrm{Cr}$ & 0,0556 \\
$\mathrm{Ni}$ & 0,0411 \\
$\mathrm{Si}$ & 0,2441 \\
$\mathrm{P}$ & 0,0195 \\
$\mathrm{~S}$ & 0,0106 \\
$\mathrm{Fe}$ & Balance \\
\hline
\end{tabular}

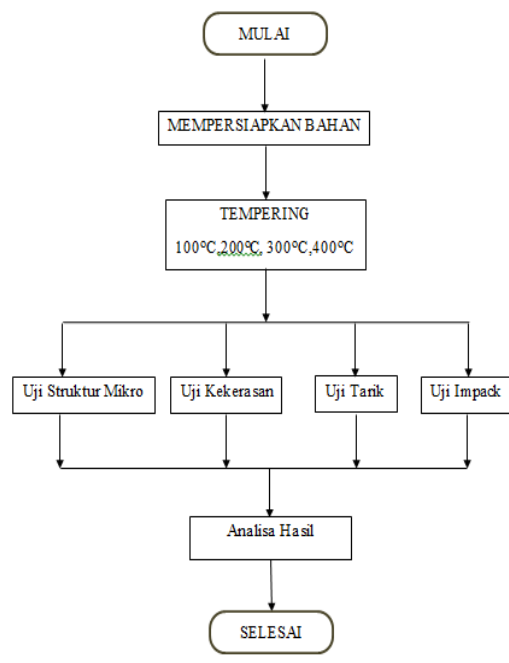

Gambar 1. Diagram alur penelitian

\section{HASIL DAN PEMBAHASAN}

Hasil uji komposisi disajikan pada tabel 1. Kadar karbon 0,46\%, Mn 0,55\%,P 0,019\%, $\mathrm{S} 0,01 \%$ menunjukkan bahwa material yang diuji termasuk klasifikasi baja $\mathrm{S} 45 \mathrm{C}$ sesuai dengan standar ASTM.

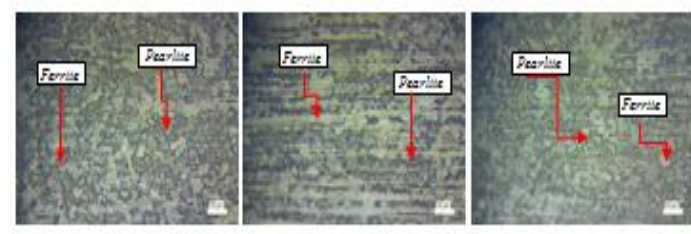

Gambar 2. Struktur mikro raw material
Untuk keterangan nama spesimen dalam gambar struktur mikro, seperti pada gambar 2 . Spesimen $700^{\circ} \mathrm{C}$ oli berarti spesimen dipanaskan dengan suhu austenisasi pada suhu $700^{\circ} \mathrm{C}$ dengan media celup oli.

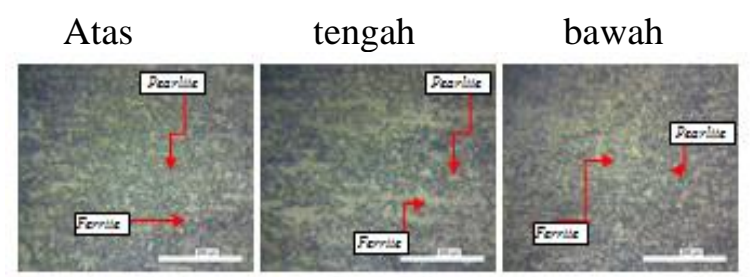

quenching $700^{\circ} \mathrm{C}$

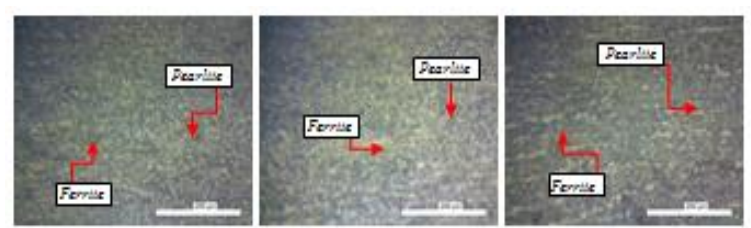

quenching $800^{\circ} \mathrm{C}$

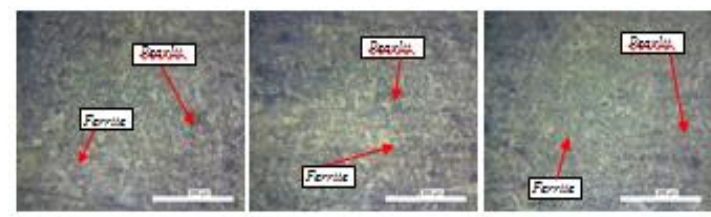

Gambar 3. Struktur mikro spesimen $100^{\circ} \mathrm{C}$

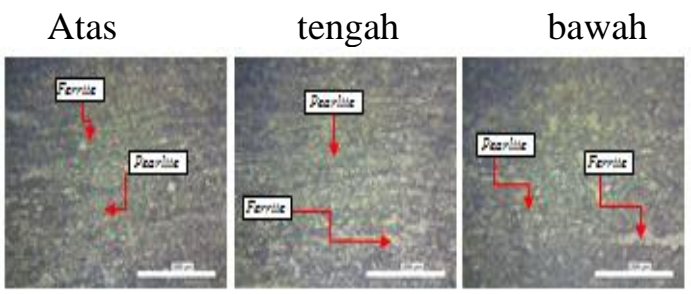

quenching $700^{\circ} \mathrm{C}$

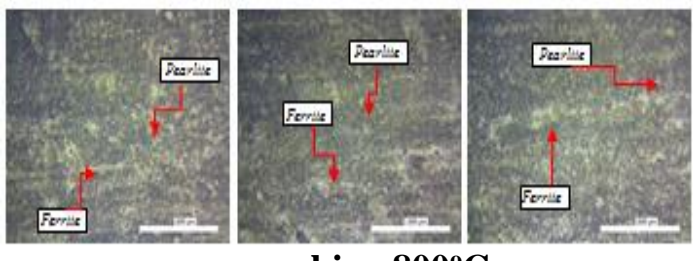

quenching $800^{\circ} \mathrm{C}$

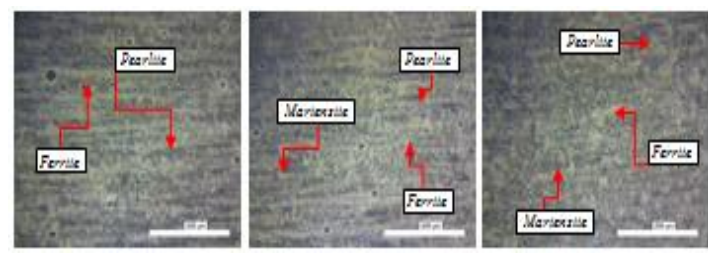

quenching $900^{\circ} \mathrm{C}$

Gambar 4. Struktur mikro spesimen $200^{\circ} \mathrm{C}$ 


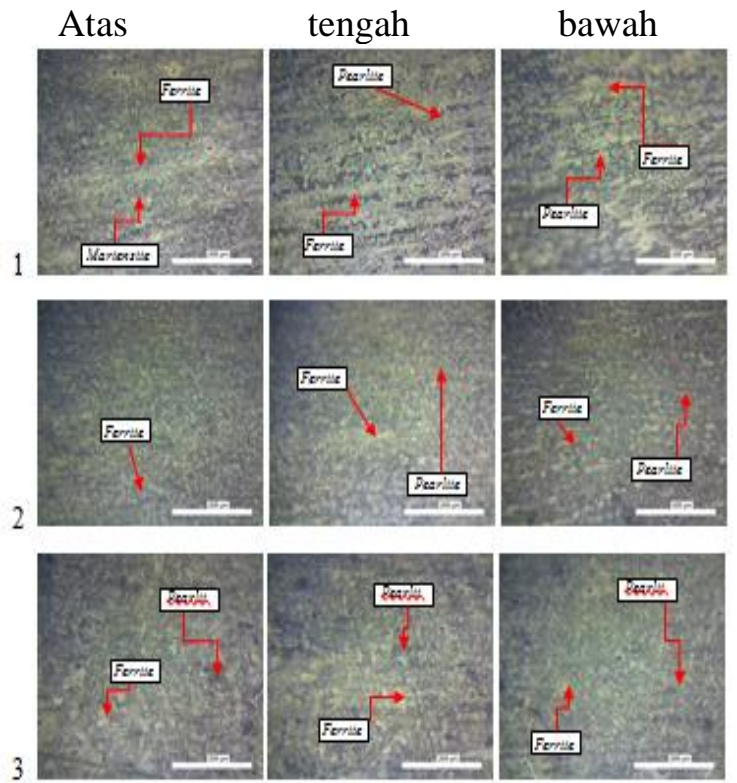

Gambar 5. Struktur mikro spesimen $300^{\circ} \mathrm{C}$

(1) quenching $700^{\circ} \mathrm{C}$

(2) quenching $800^{\circ} \mathrm{C}$

(3) quenching $900^{\circ} \mathrm{C}$

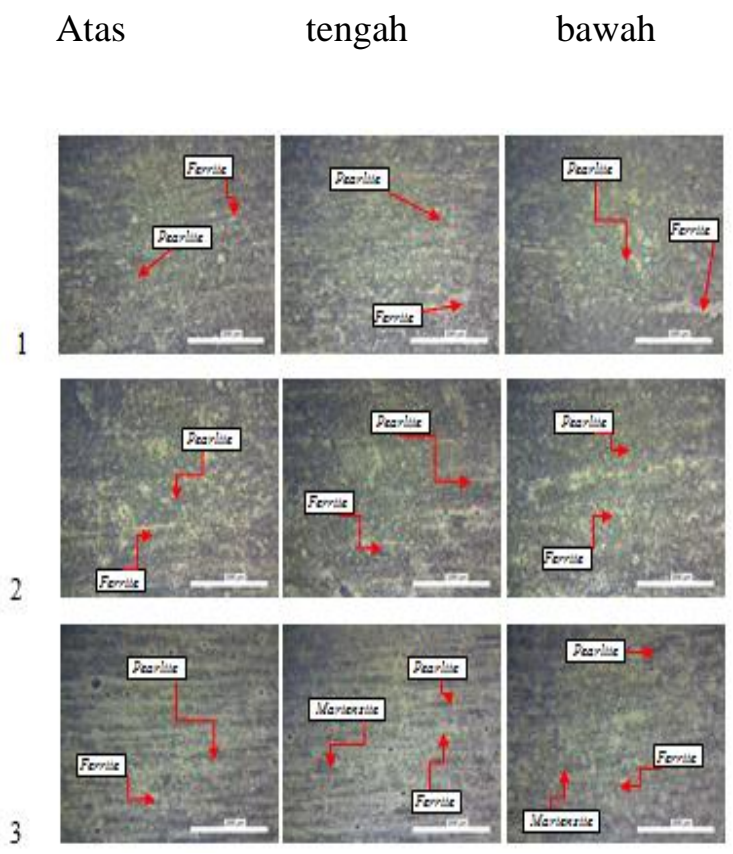

Gambar 5. Struktur mikro spesimen $400^{\circ} \mathrm{C}$

(1) quenching $700^{\circ} \mathrm{C}$

(2) quenching $800^{\circ} \mathrm{C}$

(3) quenching $900^{\circ} \mathrm{C}$

Gambar struktur mikro menunjukkan adanya perbedaan struktur mikro pada tiap variable penelitian. Pada raw material komposisi struktur mikronya lebih seimbang antara ferit dan perlitnya hal ini yang mengakibatkan kekerasannya masih rendah. Setelah di heat treatment quenching dengan media celup oli dengan variable suhu austenite $700^{\circ} \mathrm{C}, 800^{\circ} \mathrm{C}, 900^{\circ} \mathrm{Cdan}$ di tempering pada suhu $100^{\circ} \mathrm{C}, 200^{\circ} \mathrm{C}, 300^{\circ} \mathrm{C}, 400^{\circ} \mathrm{C}$ mengalami perubahan di permukaannya yaitu adanya perubahan banyaknya struktur perlite area permukaan tetapi tidak terlalu banyak sehingga pada uji kekerasannya ada peningkatan nilai kekerasannya namun tidak signifikan.

Pada spesimen dengan variabel Austenisasi $900{ }^{\circ} \mathrm{C}$ dan setiap suhu tempering dengan media celup oli terdapat struktur mikro martensit yang disertai juga dengan perlite dan ferit. Pada hasil pengujian kekerasan ini menggunakan metode Vickers yang ditunjukkan pada gambar 9, Gambar 10, Gambar 11. Spesimen mempunyai ketebalan 8 $\mathrm{mm}$, dan pada penelitian ini spesimen dibagi menjadi 20 titik, sehingga pada tiap titik uji berjarak $0.4 \mathrm{~mm}$.

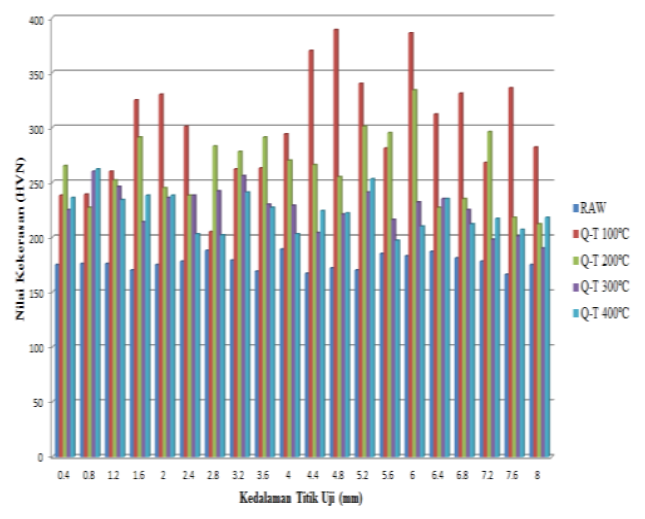

\section{Gambar 9. hasil uji kekerasan mikro Vickers quenching $700^{\circ} \mathrm{C}$}

Hasil uji kekerasan mikro Vickers quenching $700^{\circ} \mathrm{C}$ yang mana dapat dilihat bahwa tempering $100^{\circ} \mathrm{C}$ memiliki nilai kekerasan yang paling tinggi dari pada hasil tempering pada temperatur $200{ }^{\circ} \mathrm{C}, 300^{\circ} \mathrm{C}$, dan $400{ }^{\circ} \mathrm{C}$. Dimana nilai tertinggi terdapat pada titik uji ke 12 yang terletak pada bagian tengah spesimen dengan nilai kekerasan 389 HVN.

\section{Spesimen Quenching $800{ }^{\circ} \mathrm{C}$}

Hasil uji kekerasan mikro Vickers quenching $800^{\circ} \mathrm{C}$ yang mana dapat dilihat bahwa tempering $200^{\circ} \mathrm{C}$ memiliki nilai kekerasan yang paling tinggi dari pada hasil 
tempering pada temperatur $100{ }^{\circ} \mathrm{C}, 300^{\circ} \mathrm{C}$, dan $400{ }^{\circ} \mathrm{C}$. Dimana nilai tertinggi terdapat pada titik uji ke 12 yang terletak pada bagian tengah spesimen yang nilai kekerasannya $392 \mathrm{HVN}$.

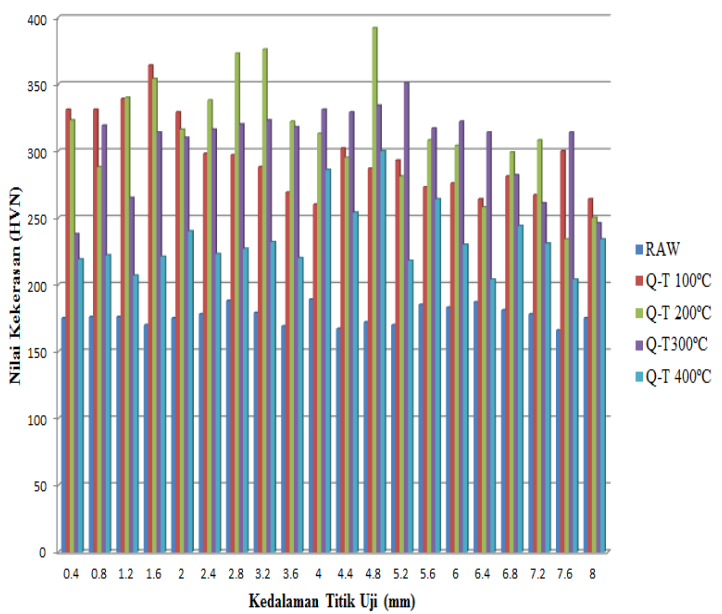

Gambar 10. hasil uji kekerasan Mikro Vickers quenching $800{ }^{\circ} \mathrm{C}$

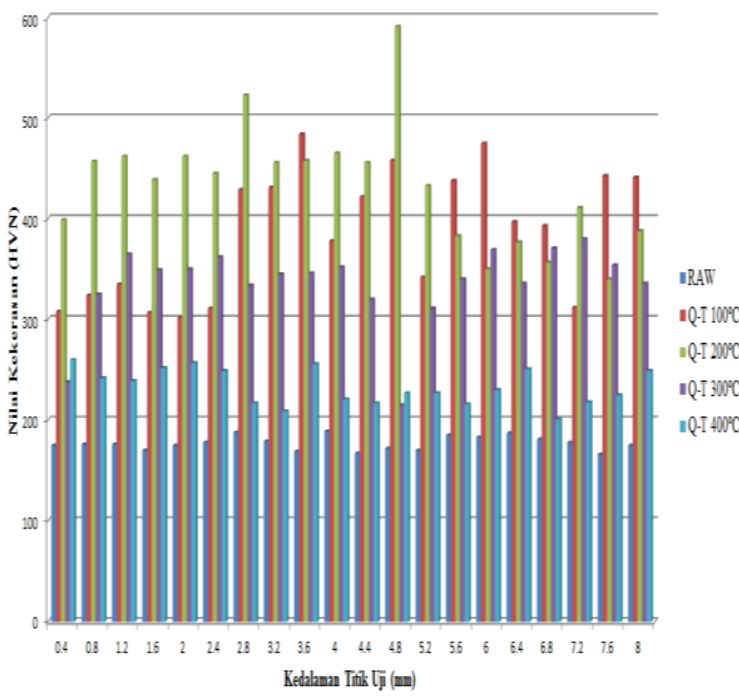

Gambar 11. Hasil Uji Kekerasan Mikro Vickers Quenching $900{ }^{\circ} \mathrm{C}$

Gambar 11. Menunjukkan bahwa perbedaan hasil antara tempering $100{ }^{\circ} \mathrm{C}, 200$ ${ }^{\circ} \mathrm{C}, 300^{\circ} \mathrm{C}$, dan $400{ }^{\circ} \mathrm{C}$ sangat terlihat. Dimana nilai tertinggi terdapat pada titik uji ke 12 dengan nilai kekerasan $591 \mathrm{HVN}$.

\section{Uji Tarik (Tensile Strength)}

Data yang didapatkan dari hasil uji tarik ditunjukkan pada Tabel 2. sebagai berikut:

\section{Tabel 3. Hasil Uji Tarik}

\begin{tabular}{cccc}
\hline No & Tempering & $\begin{array}{c}\text { Quenching } \\
\text { oli }\end{array}$ & $\begin{array}{c}\text { Hasil Uji tarik } \\
(\mathrm{MPa})\end{array}$ \\
\cline { 3 - 4 } & & & $\mathrm{max}$ stress \\
\hline 1 & & $\mathrm{R} \mathrm{M}$ & 548 \\
2 & & $700^{\circ} \mathrm{C}$ & 818 \\
3 & $100{ }^{\circ} \mathrm{C}$ & $800^{\circ} \mathrm{C}$ & 904 \\
4 & & $900^{\circ} \mathrm{C}$ & 1063 \\
5 & & $700^{\circ} \mathrm{C}$ & 680 \\
6 & $200{ }^{\circ} \mathrm{C}$ & $800^{\circ} \mathrm{C}$ & 877 \\
7 & & $900^{\circ} \mathrm{C}$ & 858 \\
8 & & $700^{\circ} \mathrm{C}$ & 664 \\
9 & $300{ }^{\circ} \mathrm{C}$ & $800^{\circ} \mathrm{C}$ & 741 \\
10 & & $900^{\circ} \mathrm{C}$ & 883 \\
11 & & $700{ }^{\circ} \mathrm{C}$ & 749 \\
12 & $400{ }^{\circ} \mathrm{C}$ & $800^{\circ} \mathrm{C}$ & 719 \\
13 & & $900^{\circ} \mathrm{C}$ & 912 \\
\hline
\end{tabular}

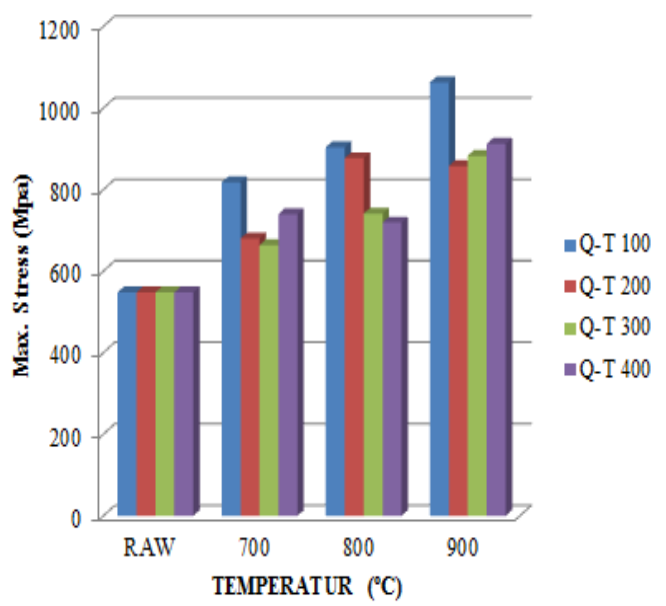

\section{Gambar 12. Grafik Hasil Uji Tarik}

Dilihat dari grafik hasil uji tarik pada Gambar 12 dapat dilihat bahwa setelah dilakukan proses tempering dengan temperature $100{ }^{\circ} \mathrm{C}, 200{ }^{\circ} \mathrm{C}, 300{ }^{\circ} \mathrm{C}$ dan $400{ }^{\circ} \mathrm{C}$ spesimen mengalami penurunan kekuatan uji tarik. Kekuatan uji tarik dengan nilai Max Stress tertinggi adalah pada variabel pemanasan suhu austenisasi $900^{\circ} \mathrm{C}$ tempering dengan temperature $200{ }^{\circ} \mathrm{C}$ yaitu sebesar 1063 $\mathrm{MPa}$, dan nilai Max Stress terendah terdapat pada variable tempering $300{ }^{\circ} \mathrm{C}$ dan quenching $700^{\circ} \mathrm{C}$. Pada pengujian impak ini menggunakan metode Charpy dan hasil pengujian impak seperti ditunjukkan pada Tabel 4 dan Gambar 13. 
Tabel 4. Hasil Uji Impak

\begin{tabular}{|c|c|c|c|c|c|}
\hline No & Variabel & $\begin{array}{l}\text { Tebal } \\
(\mathbf{m m})\end{array}$ & $\begin{array}{r}\text { Lebar } \\
(\mathbf{m m})\end{array}$ & $\begin{array}{c}\text { Energi } \\
\text { (J) }\end{array}$ & $\begin{array}{c}\text { Harga } \\
\text { Impak } \\
(\mathrm{J} / \mathrm{mm} 2)\end{array}$ \\
\hline 1 & $\begin{array}{c}\text { Raw } \\
\text { Material }\end{array}$ & 8,35 & 8,04 & 20 & 0.30 \\
\hline 2 & $\begin{array}{c}700 \text { Oli } \\
\text { T200 }\end{array}$ & 8,35 & 8,04 & 18 & 0.27 \\
\hline 3 & $\begin{array}{c}800 \text { Oli } \\
\text { T200 }\end{array}$ & 8,33 & 8,08 & 20 & 0.30 \\
\hline 4 & $\begin{array}{c}900 \text { Oli } \\
\text { T200 }\end{array}$ & 8,33 & 8,05 & 25 & 0.37 \\
\hline 5 & $\begin{array}{c}700 \text { Oli } \\
\text { T300 }\end{array}$ & 8,29 & 8,04 & 20 & 0.30 \\
\hline 6 & $\begin{array}{c}800 \text { Oli } \\
\text { T300 }\end{array}$ & 8,83 & 8,02 & 22 & 0.31 \\
\hline 7 & $\begin{array}{c}900 \text { Oli } \\
\text { T300 }\end{array}$ & 8,52 & 8,09 & 25 & 0.36 \\
\hline 8 & $\begin{array}{c}700 \text { Oli } \\
\text { T400 }\end{array}$ & 8,87 & 8,05 & 27 & 0.38 \\
\hline 9 & $\begin{array}{c}800 \text { Oli } \\
\text { T400 }\end{array}$ & 8,46 & 8,03 & 22 & 0.32 \\
\hline 10 & $\begin{array}{c}900 \text { Oli } \\
\text { T400 }\end{array}$ & 8,61 & 8,09 & 28 & 0.40 \\
\hline
\end{tabular}

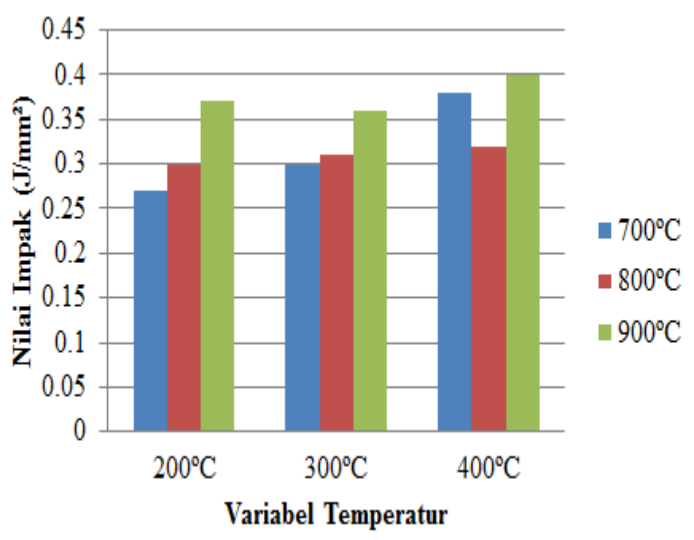

\section{Gambar 11. Grafik uji impak}

Pada hasil pengujian impak yang ditampilkan pada Gambar 11 didapatkan hasil tertinggi yaitu pada variabel tempering pada temperature $\quad 400 \quad{ }^{\circ} \mathrm{C}$ dan temperature quenching $900^{\circ} \mathrm{C}$ yaitu energi yang diserap sebesar 28 Joule dan harga impaknya sebesar $0.40 \mathrm{~J} / \mathrm{mm}^{2}$. Dan harga impak terendah pada temperature tempering $200^{\circ} \mathrm{C}$ dan temperature quenching $700{ }^{\circ} \mathrm{C}$ yaitu sebesar $0,27 \mathrm{~J} / \mathrm{mm}^{2}$.

\section{KESIMPULAN}

Pengamatan struktur mikro pada plat baja S45C setelah di tempering $100{ }^{\circ} \mathrm{C}$ dari pemanasan suhu austenite quenching $700^{\circ} \mathrm{C}$, $800^{\circ} \mathrm{Cdan} 900^{\circ} \mathrm{C}$ tidak ada fasa martensit namun fasa perlite menjadi lebih banyak dari pada fasa ferite pada spesimen sebelum dilakukan proses heat treatment. Untuk variable suhu tempering $200^{\circ} \mathrm{C}, 300^{\circ} \mathrm{C}, 400{ }^{\circ} \mathrm{C}$ terdapat beberapa martensit pada pemanasan suhu austenite $900^{\circ} \mathrm{C}$ dan masih di dominasi fasa perlite dan ferite.

Pada pengujian nilai kekerasan mikro Vickers penelitian ini didapat nilai tertinggi adalah pada variabel temperatur tempering $200^{\circ} \mathrm{C}$ quenching $900^{\circ} \mathrm{C}$ yaitu sebesar 591 HVN dan nilai terendah terdapat pada spesimen dengan temperatur tempering $400^{\circ} \mathrm{C}$ quenching $900^{\circ} \mathrm{C}$ yaitu dengan nilai 197 HVN. Jadi semakin tinggi temperatur tempering semakin rendah nilai kekerasannya.

Pengujian kekuatan tarik pada spesimen yang telah dilakukan proses tempering mengalami perubahan kekuatan tarik dan nilai maksimum kekuatan tarik yang didapat dari penelitian ini adalah $1063 \mathrm{~N} / \mathrm{mm}^{2}$ (MPa) yaitu pada variabel temperatur tempering $100^{\circ} \mathrm{C}$. quenching $900^{\circ} \mathrm{C}$. Dan pada temperatur tempering $400^{\circ} \mathrm{C}$, yang rata-rata nilai Max Stress nya lebih rendah. Semakin tinggi temperatur tempering semakin rendah nilai Max Stress.

Pada uji impak spesimen yang telah dilakukan proses tempering mengalami perubahan dari pada nilai impak spesimen yang belum dilakukan heat treatment (raw material). Pada nilai impak tertinggi didapat dari variabel temperatur tempering $400^{\circ} \mathrm{C}$ quenching $900^{\circ} \mathrm{Cyaitu}$ sebesar 0,40 $\mathrm{J} / \mathrm{mm}^{2}$ dan nilai terkecil didapat pada variabel temperatur tempering $200^{\circ} \mathrm{C}$ quenching $900^{\circ} \mathrm{C}$ dengan yaitu sebesar $0,27 \mathrm{~J} / \mathrm{mm}^{2}$. Dapat disimpulkan bahwa semakin tinggi temperatur tempering maka semakin tinggi pula harga impaknya.

\section{DAFTAR PUSTAKA}

ASTM E8. (2010). ASTM E8/E8M standard test methods for tension testing of metallic materials 1. Annual Book of ASTM Standards 4, C, 1-27. https://doi.org/10.1520/E0008

Handoyo, Y. (2015). Pengaruh Quenching dan Tempering pada Baja JIS Grade S45C Terhadap Sifat Mekanis dan Struktur Mikro Crankshaft. In Jurnal Ilmiah Teknik Mesin. jurnal.unismabekasi.ac.id. https://jurnal.unismabekasi.ac.id/index.p $\mathrm{hp} / \mathrm{jitm} /$ article/download/350/265

Mizhar, S., \& Suherman, S. (2011). Pengaruh 
Perbedaan Kondisi Tempering Terhadap Struktur Mikro dan Kekerasan dari Baja AISI 4140. In Jurnal dinamis.

Purwanto, H. (2011). Analisa Quenching Pada Baja Karbon Rendah Dengan Media Solar. Momentum, 7(1), 36-40.

Purwanto, Helmy, Soenoko, R., Purnowidodo, A., \& Suprapto, A. (2016). Pengembangan Material Tahan Balistik Sebagai Bahan Kendaraan Tempur di Indonesia: Review. Seminar Nasional Inovasi Dan Aplikasi Teknologi Di Industri (Seniati), ISSN : 208, A.127-132.

Sularso, K. S. (2004). Elemen Mesin. Jakarta, Th.

Suroto, A., \& Sudibyo, B. (1983). Ilmu Logam Metallurgy (A. M. College (ed.)). ATMI PRESS

Yurianto, Y., Soenoko, R., \& Soeprapto, W. (2018). Optimasi Parameter Quenching dan Tempering pada HRP Steel Lokal sebagai Baja Armor Nasional. Rekayasa Mesin.

https://rekayasamesin.ub.ac.id/index.php /rm/article/view/435 